\title{
Small-hydro Floodgate Automation Using Induction Generator in Isolated Operation
}

\author{
Alexandre Viana Braga*, Angelo José Junqueira Rezek*, Valberto Ferreira da Silva*, Augusto Nelson \\ Carvalho Viana*, Edson da Costa Bortoni*, Walter Denis Cruz Sanchez **
}

\begin{abstract}
A system designed to protect against generator under-voltage or overvoltage, through the use of an automatic hydraulic floodgate in a micro-hydro power plant, using induction generator in a stand-alone operation, was implemented in a micro-station hydroelectric power $30[\mathrm{~kW}]$. The proposed system uses 24[V] batteries in a circuit and these are always kept ready using a battery charger, designed especially for the microstation operation. The time of descent and the gate rise time, are approximately one minute and a half. Tests were performed for the operation of the gate. The proposed protection system was robust, efficient, simple and reliable.
\end{abstract}

Keywords - Induction generator; voltage control, ballast load, floodgate automatic operation

\section{Introduction}

The isolated generation in hydroelectric micro-stations with an induction generator has been the subject of extensive research, because this type of electric machine is easy to operate, easy maintenance, and lower in cost compared to the synchronous machine, mainly in the range from 0.5 to $50[\mathrm{~kW}]$ [1]. However, the induction generator can not by itself provide magnetizing or reactive power. To establish its magnetic field it absorbs reactive power from synchronous generators, in the case of parallel operation, or from capacitors, in the case of isolated operation.

In isolated operation of a hydroelectric micro-station a way to prevent substantial increases speed of the generator group is needed. The speed control is traditionally done by mechanical speed regulators similar to those used in large hydroelectric power plants, which are used to regulate the water flow turbine as the load demand changes. However, with the using of low cost induction generator, a mechanical speed regulator is complex and expensive [2]. As shown in this paper, the generated voltage is controlled, while the frequency varies in a narrow range. This means that the generator group speed also varies in a narrow range. However, there may be disturbances in the speed of the generator group, with dangerous voltages for the generator and also to the main load of the rural community served by hydroelectric microstation. Due to the need for facility and simplification of operation, we opted for the use of a hydraulic gate, where the components were contained in one control cabinet, and the automation will be described in this work. The hydroelectric

\footnotetext{
* Federal University of Itajubá (UNIFEI)

**Technological Federal University of Paraná (UTFPR)

Corresponding author:
}

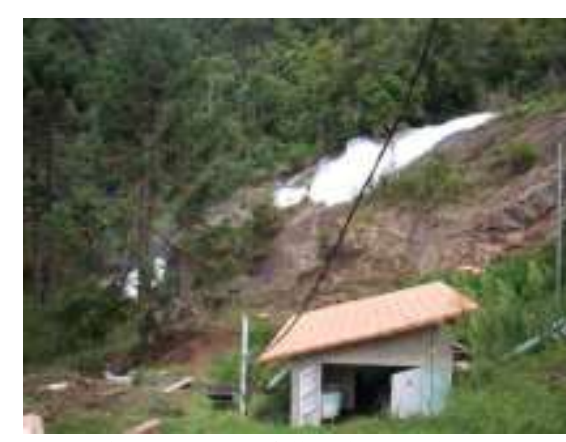

Figure 1: Waterfall and power house

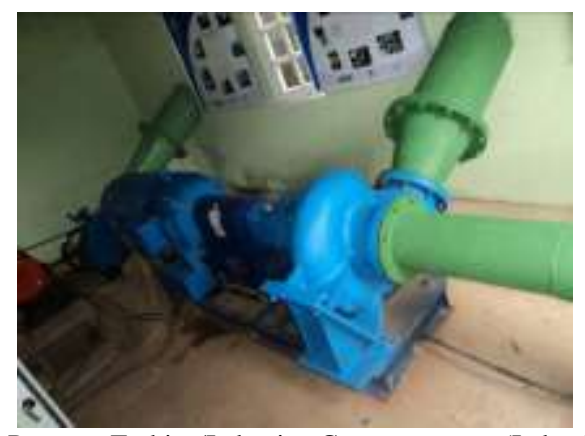

Figure 2: Pump as Turbine/Induction Generator group(Induction motor nameplate data: $45[\mathrm{~kW}], 60[\mathrm{~Hz}], 220 / 380 / 440[\mathrm{~V}], 1780[\mathrm{RPM}]$, power factor: $87 \%$, efficiency: $93.1 \%$, manufacturer: WEG)

micro-station, where the protection system described in this paper was implemented, is shown in Figure 1. The generator group, a pump functioning as turbine and an induction motor functioning as generator, is shown in Figure 2. This microstation is located in Boa Esperança Farm[8]. With 211 [hectares] [3], this farm is located [4] in the Mountain range Municipality of Delfim Moreira, in southern Minas Gerais, Brazil.

\section{Electronic Load Controller}

Using an electronic control board, whose description is not subject of this work, the ballast load is controlled to maintain the generated voltage in a narrow range of variation. The frequency control happens naturally, that is, if the voltage is around its nominal value, the corresponding frequency will also be close to their nominal value. The control narrows the load voltage variation, by using the controlled ballast load, 




Figure 3 - Illustration of the load control system

when it has significant variations from the main load.

In laboratory, isolated generation employing induction generators associated with capacitor groups, can use the static compensator arrangement of reactive power, the so called SVC (Static Var Compensation), which consists of capacitors associated with reactors controlled by thyristors for voltage control. The frequency, on the other hand, is no controlled [5].

A contribution and novelty of the present work is that it enables the application of induction generators in rural areas with only voltage regulation. The proposed system is therefore simpler as it unifies the control of voltage and frequency, differing in this respect, from the most common applications encountered in literature, which include two separate controls voltage and frequency.

So, simplification of the operations and maintenance of electric generators for micro-plants is always very helpful, especially with those applied to rural areas. Also in the work described in this paper, a speed regulator, which acts on the control flow of water, was not used. However, the load controller is used, which is simpler and presents a lower cost for using in small hydroelectric plants.

The idea of the electronic load controller is shown in Figure 3. This controller operates without water flow control, with the valve fully open. There is a main load, which is the load of the farm itself. There is also a load connected in parallel, called a ballast load, controlled by the three-phase AC voltage regulator, with thyristors in anti-parallel per phase, controlling the firing angle of the three-phase AC controller, from $0^{\circ}$ (maximum ballast load) to $180^{\circ}$ (minimum ballast load). Thus, for the main load input (increased load), there is a generator voltage drop and the voltage regulator automatically decreases the ballast load, and vice versa, so that the induction generator always "sees" a load and "constantly" maintains the voltage and the frequency varying in a narrow range, tolerated by loads of rural areas. The ballast load is made up of heating elements immersed in water, for use in a small thermal pool of the farm.

Whereas a machine load increases, implies a decrease of the voltage and frequency and for a load decrease, implies the opposite. This is undesirable, so that the voltage and frequency should be maintained in an acceptable range for loads in rural



Figure 4 - Per phase equivalent circuit of the controlled ballast load

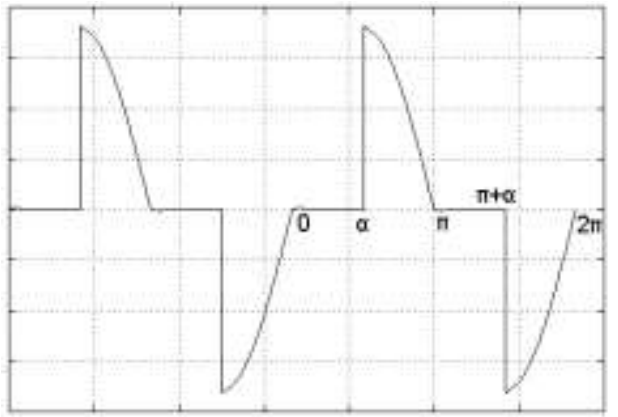

Figure 5 - Per phase output voltage applied to the ballast load, for a firing angle of $90^{\circ}$

areas. For this purpose, it is required to include a voltage regulation system of the induction generator; as an option one can use a ballast load control system.

In the ballast load control loop, a voltage reference value is adjusted, taking as feedback the voltage from the voltage transducer (rectified voltage of the machine by means of feeding three-phase diode bridge resistance in the direct current side). The control system operates controlling the ballast load, in consequence there is an increase or decrease in the voltage applied to this load, resulting in an adjustment of the voltage applied to the main load. A general view of this control system can be seen in [6].

The generator "sees", therefore that there is always an almost "constant" load, which implies that the voltage generated is maintained in a narrow range of variation (around the nominal value), varying within an allowable range.

Thus, increasing the plant's main load constitutes a ballast load decrease, and vice-versa (i.e. a decrease in the main load implies that an increased ballast load). This is achieved by automatically increasing or decreasing the power of the ballast load by using the three-phase AC controller, which consists of antiparallel thyristors per phase, feeding the stock heating elements. The voltage applied to the ballast heating elements is controlled by varying the firing angle of thyristors connected in anti-parallel per phase, feeding the ballast resistance load.

Figure 4 illustrates the power per phase equivalent circuit for explaining the principle of the operation of the ballast load controller.

Figure 5 shows the waveform of the per phase output voltage applied to the ballast load at a firing angle of $90^{\circ}$. 


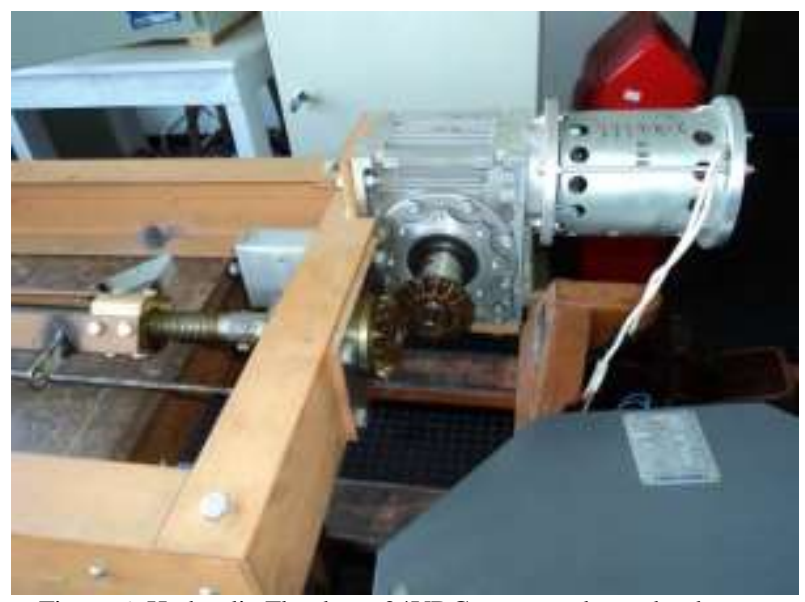

Figure 6: Hydraulic Floodgate 24VDC motor and speed reducer.

Thus, for the $180^{\circ}$ firing angle, the effective value of the voltage applied to the ballast load resistance is zero, and this voltage is being gradually increased by decreasing the firing angle of the thyristors. The power dissipated in the ballast load bank for water heating is proportional to the square of the effective value of this applied voltage load, achieving in this way a control of the power of the ballast.

\section{Implementation of the Protection System}

The protection system for under- and overvoltage situations of the induction generator was implemented. Ward brand three phases analogical timed relays, model UMX-321 for overvoltage and model UMX-320 for under-voltage [7], were installed. The objective was to detect an under- or overvoltage situation and arrange an emergency closure system. Every electronic circuit is subject to the occurrence of failures. Therefore, a surge can occur, for example, if the Semikron MP410T board is damaged or if there is some failure of the ballast load control circuit. Thus, the pressure drop causes the turbine generator set to shoot high speed, causing the voltage generated to substantially increase, causing a bus overvoltage. There is therefore a need to control the emergency closure of the gate at the entrance of the penstock, in order to avoid no mechanical damage to the set. Figure 6 shows the speed reducer of the floodgate. Figure 7 shows a general view of the floodgate in mounting phase. Figure 8 shows the floodgate mounted at the entrance of the pipe. This automatic emergency lock gate is implemented by activating the DC 24[V], $1[\mathrm{CV}]$ motor (the voltage supplied by batteries), which is automatically triggered.

An under-voltage situation can also occur. For example, when it rains the adductor canal carries leaves and small branches that clog the retention grids. Thus, the water flow decreases a lot, thereby decreasing the rotation of the machine, occurring thus a decreases in the voltage generated by the machine, resulting in an under-voltage.

On the farm there are three-phase induction motors, which can burn when long periods of under-voltage occur. For this

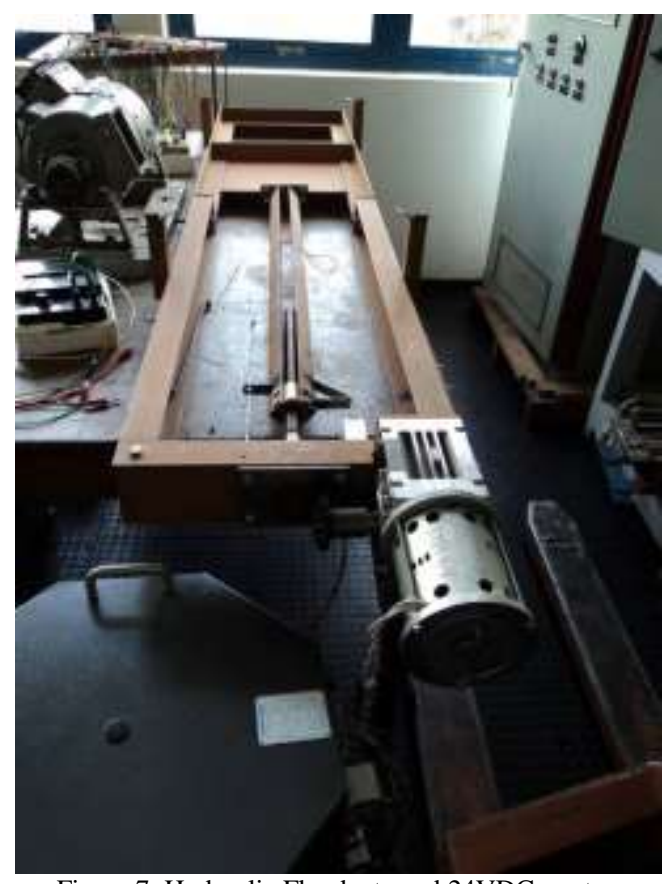

Figure 7: Hydraulic Floodgate and 24VDC motor.

reason the under-voltage relay is crucial to control the emergency closing of the gate.

Figure 9 shows the electrical diagram of the under- and overvoltage relays. Figure 10 shows the command circuit of this system. In the presence of overvoltage or under-voltage, the respective $\mathrm{C} 4$ and $\mathrm{C} 5$ relay contacts, shown in Figure 10, are triggered by energizing the $\mathrm{K} 1 \mathrm{c}$, thus activating the $\mathrm{DC}$ motor, in order to close the gate completely, until the descent limit contact be touched (the completely closed gate status), which opens the circuit and powers off K1c, thus stopping the DC motor. When the gate is closed, generation is stopped; it may, however, be possible to normalize the voltage after this, in a new operation procedure. To open the gate push the open button (B1), which turns on $\mathrm{K} 2 \mathrm{c}$, thus activating the DC motor in order to open the gate completely), until the rise limit contact be touched (the completely open gate status), which opens the circuit and turns off K2c by stopping the DC motor. The command circuit also has the C6 switch (bypass), which has the function of manual override to lock the gate in case of failures in relays, testing or any other needs. On the front panel of the control and protection board the timed overvoltage and under-voltage relays used are calibrated at $1.15[\mathrm{pu}]$ and $0.85[\mathrm{pu}]$ respectively, with a time delay of $5[\mathrm{~s}]$ each. The batteries only work at the time of closing and opening the gate and must always be kept charged. Figure 8 shows the charging circuit of the batteries that power the command circuit of Figure 7 and promote the activation of DC motor of $24[\mathrm{~V}]$ when necessary. In the circuit of the battery charger in Figure 11 there is a half-wave rectifier (half-wave), and for this function a power diode was used. In series with this diode there is a tubular resistor with nickel-chromium resistive element of $10[\Omega]$ and power $1250[\mathrm{~W}] 2.6[\mathrm{~A}]$ and permanent flow. The two batteries being charged are connected in series. In parallel to the batteries in series there 


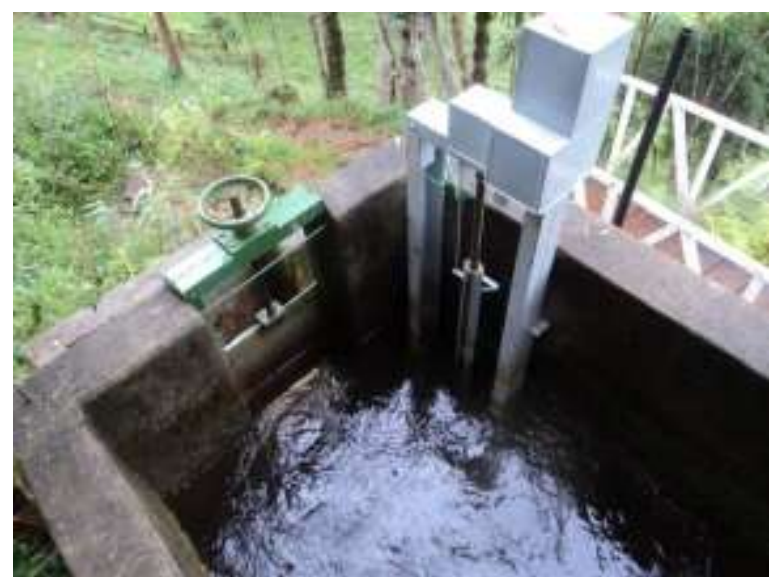

Figure 8: The floodgate at right is actuated by a DC 24[V] motor located at the top. This voltage is supplied by batteries. The entrance of the pipe is located under water.



are 4 resistors of $100[\Omega]$ each, totaling an equivalent parallel resistance of $25[\Omega]$ dissipating a power of $23[\mathrm{~W}]$. These resistors produce a load in the battery charging system for it becomes working with increasing the life of the same. Relays of under-voltage and overvoltage are fed in 24[V]. The gate of the control circuit is also powered by the batteries in 24[V]. Figure 12 shows the control cabinet where the electrical elements of the protection system are installed.

\section{Conclusion}

The use of a protection system using a floodgate to close the penstock entrance in the cases of under-voltages or overvoltage occurrences was satisfactory.

There was also reduction in size of the modules of the implemented protection system.

The time of the floodgate closing in a test was approximately one minute and a half. This time is also satisfactory, because is acceptable for loads in rural areas.

This small-hydro power plant worked seamlessly without skilled labor for its operation for a year and a half. During this period no component of the protection system failed, thus proving that the proposed protection system is robust and reliable.

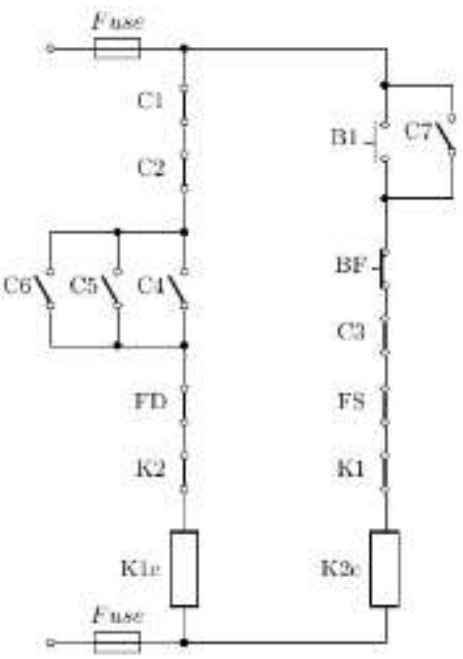

Figure 10: Command circuit diagram of the floodgate (Legend: K1c - coil of the contactor for floodgate closing; K2c - coil of the contactor for floodgate opening; K1 and K2 - interlocking contacts; B1 - button for opening; B1 button for opening; $\mathrm{BF}$ - button for stop the opening; $\mathrm{C} 2$ - thermal relay contact of K1c; C3 - thermal relay contact of K2 contactor; C4 - overvoltage relay contact; C5 - under-voltage relay contact; C6 - bypass switch; C7 sealing switch of K2 contactor; FD - descent limit contact; FS - rise limit contact; $\mathrm{C} 1$ - permissible key for the floodgate descent)

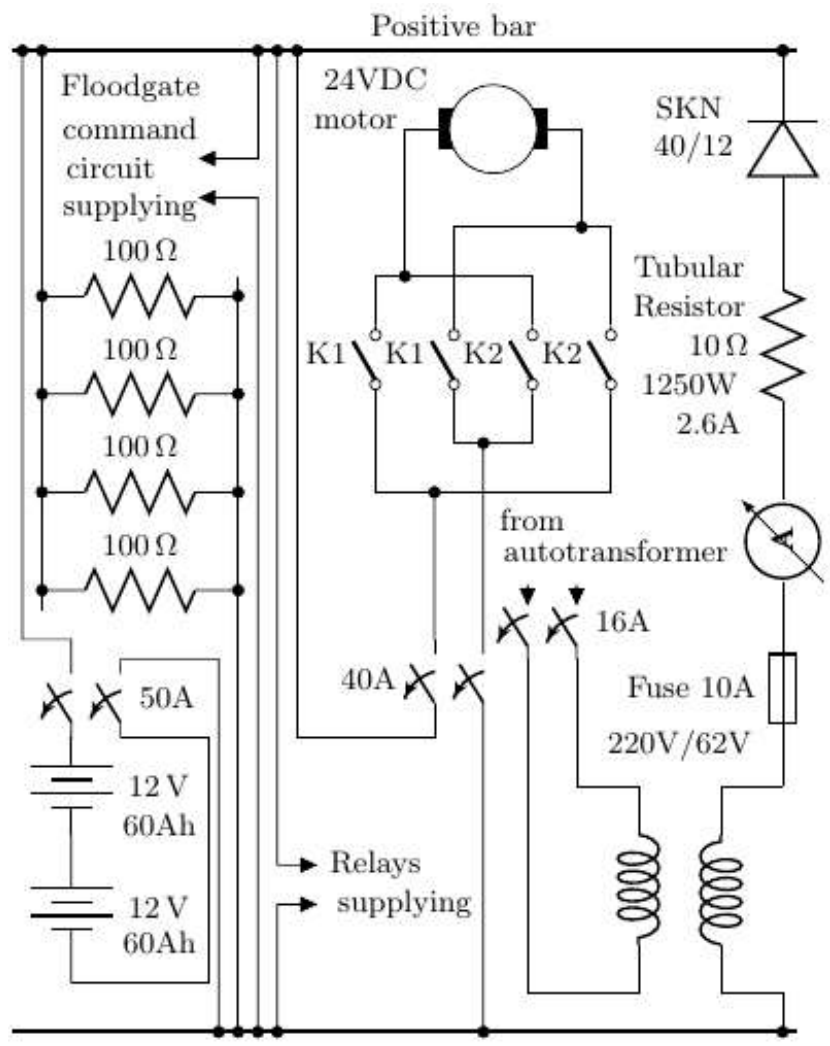

Negative bar

Figure 11: Battery charger circuit (Legend: K1 - contact of the contactor for floodgate closing; K2 - contact of the contactor for floodgate opening; SKN $40 / 12$ is the diode of the battery charger, what is essential for the protection of the system.) 


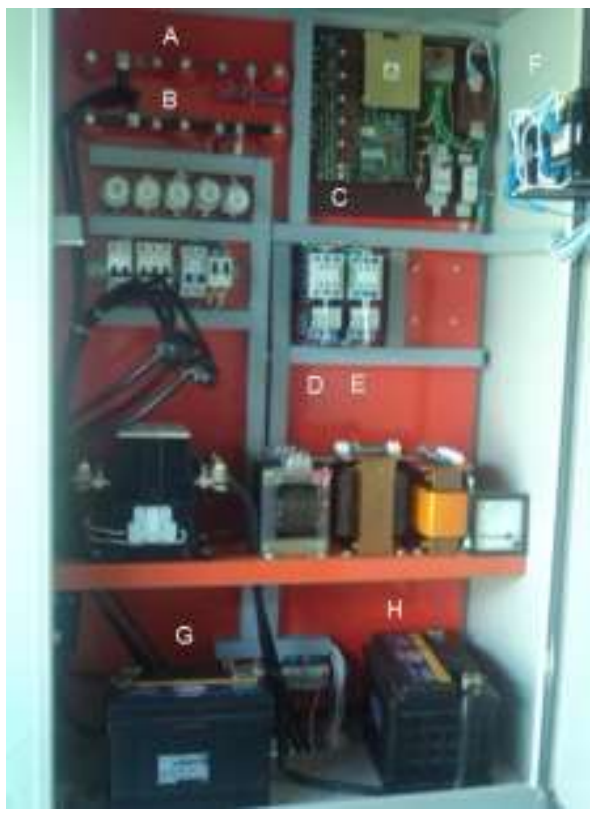

Figure 12: Power house cabinets (Legend: A - positive bar; B - negative bar; C - Semikron MP410T board; D - K1 contactor for floodgate descent; E - K2 contactor for floodgate rising; F - under-voltage and overvoltage relays; $\mathrm{G}$ and $\mathrm{H}$ - batteries).

It should be noted that an operating manual was written and has been used without problems. This is important because, an operation which requires much technical knowledge and skills of trained personnel would make not feasible the implementation of the project in rural areas. For successful operation, due to the factors mentioned above it is important that the operation of the generator be simple.

Also, in the majority of implemented micro-stations, there is no protection against generator under- and overvoltage. There is therefore a need to control the emergency closure of the gate at the entrance of the penstock, in order to avoid no dangerous mechanical damage to the set, in the case of overspeed, which can also cause dangerous generator overvoltage. In the case of under-speed, under-voltage occurs, needing also the stopping of the generator group. Therefore, an important contribution of the work is the proposition of the implementation of this described simple, robust, efficient, autonomous(batteries supplied) and of lower cost automatic protection system for using in rural areas micro-stations.

\section{Acknowledgment}

The authors would like to thank the Ministry of Mines and Energy for the use of the micro-hydroelectric power plant at the Boa Esperança Farm, which functions as the Advanced Laboratory for micro-hydroelectric power plants by agreement between the Federal University of Itajubá through the Light for All program; the Foundation for Research Support of the State of Minas Gerais (FAPEMIG) for financing the research project (Research Project TEC-APQ-00201-09) "Digital control applied to isolated induction generator for serving small rural communities", which allowed the development of this project; the Municipality of Itajubá for financial support for the project. The authors also would like to thank the old
Balteau Transformers, Schlumberger, Areva, and current Alstom, located in the city of Itajubá, Mantiqueira Mountain Range, in the south of Minas Gerais State, Brazil, by the donation of two potential transformers. Finally, the authors would like to thank Magneti Marelli, the company that sponsored the project by donating batteries used in emergency closing of the gate system. The authors would like also to thank Mr. Luiz Carlos, the owner of the Boa Esperança Farm, for his friendly reception of our technical team and also all the people that contributed to the success of this research work.

\section{References}

[1] J. M. Chapallaz, J. D. Ghali, P. Eichenberger, G. Fischer, "Manual on Induction Motors Used as Generators", MHPG Series, Vieweg and Sohns Verlagsgesellshaft, 1990.

[2] M. G. Simões, F. A. Farret, "Alternative energy systems, design and analysis with induction generators", CRC Press, Taylor \& Francis Group, 2nd Edition, Flórida, 1995.

[3] KSB. "Hydropower from pump as turbines". World Pumps, 2012(1):1415,2012 . ISSN 0262-1762. http://www.sciencedirect.com/science/article/pii/s0262176211703935

[4] Location map (in Portuguese). Available at www.fazendaboa.com.br/site/como , [accessed:October 2, 2014].

[5] A. V. Braga, "Modelling, adjustment and implementation of a voltage control system for the induction generator" (in Portuguese), Master's thesis, Federal University of Itajubá, 2002. http://saturno.unifei.edu.br/bim/0031621.pdf

[6] A. V. Braga, A. J. J. Rezek, A. N. C. Viana, E. C. Bortoni, W. D. C. Sanchez, "Digital control applied to induction generator, isolated operation for use in rural areas" (in Portuguese). $10^{\text {th }}$ IEEE/IAS Conference in Industry Applications (INDUSCON), 2012. http://www.eletrica.ufpr.br/anais/induscon/2012/Data/iREP1588.pdf.

[7] Catalog data (in Portuguese). Available at www.ward.com.br/umx310.html, [accessed: October 2, 2014].

About Authors:

The authors are with the research group of electrical machines and drives - Electrical Engineering Institute - UNIFEI. 